\title{
Three hybrid intelligent models in estimating flyrock distance resulting from blasting
}

\author{
Mohammadreza Koopialipoor $^{1} \cdot$ Ali Fallah $^{2} \cdot$ Danial Jahed Armaghani $^{3} \cdot$ Aydin Azizi $^{4} \cdot$ Edy Tonnizam Mohamad $^{5}$
}

Received: 20 November 2017 / Accepted: 26 February 2018 / Published online: 3 March 2018

(c) The Author(s) 2018. This article is an open access publication

\begin{abstract}
Flyrock is an adverse effect produced by blasting in open-pit mines and tunnelling projects. So, it seems that the precise estimation of flyrock is essential in minimizing environmental effects induced by blasting. In this study, an attempt has been made to evaluate/predict flyrock induced by blasting through applying three hybrid intelligent systems, namely imperialist competitive algorithm (ICA)-artificial neural network (ANN), genetic algorithm (GA)-ANN and particle swarm optimization (PSO)-ANN. In fact, ICA, PSO and GA were used to adjust weights and biases of ANN model. To achieve the aim of this study, a database composed of 262 datasets with six model inputs including burden to spacing ratio, blast-hole diameter, powder factor, stemming length, the maximum charge per delay, and blast-hole depth and one output (flyrock distance) was established. Several parametric investigations were conducted to determine the most effective factors of GA, ICA and PSO algorithms. Then, at the end of modelling process of each hybrid model, eight models were constructed and their results were checked considering two performance indices, i.e., root mean square error (RMSE) and coefficient of determination $\left(R^{2}\right)$. The obtained results showed that although all predictive models are able to approximate flyrock, PSO-ANN predictive model can perform better compared to others. Based on $R^{2}$, values of $(0.943,0.958$ and 0.930$)$ and $(0.958,0.959$ and 0.932$)$ were found for training and testing of ICA-ANN, PSO-ANN and GA-ANN predictive models, respectively. In addition, RMSE values of $(0.052,0.045$ and 0.057$)$ and $(0.045,0.044$ and 0.058$)$ were achieved for training and testing of ICA-ANN, PSO-ANN and GA-ANN predictive models, respectively. These results show higher efficiency of the PSO-ANN model in predicting flyrock distance resulting from blasting. Moreover, sensitivity analysis shows that hole diameter is more effective than others.
\end{abstract}

Keywords Flyrock · Genetic algorithm · Particle swarm optimization · Imperialist competitive algorithm

\section{Introduction}

As a common solution to eliminate the rock mass, blasting operations are used in some engineering works such as tunnel excavation, road construction, and hydraulic channels [1]. Most of the explosive operations have a lot of energy that can have impacts on the environment and surrounding areas [2-6]. The common environmental issues of blasting are flyrock, air overpressure, back-break and ground vibration [7-11]. Flyrock can cause the most important effects of damages among them according to several scholars [12].

\footnotetext{
Mohammadreza Koopialipoor

Mr.koopialipoor@aut.ac.ir

Aydin Azizi

Aydin.Azizi@gutech.edu.om
}

Extended author information available on the last page of the article
In flyrock, the parameters of charge confinement, mechanical strength of the rock mass, explosive energy have an important relationships with each other [13]. Based on some researches, any mistakes in designing these parameters will result in flyrock $[13,14]$. When flyrock phenomena has happened, a lot of fragmented rocks will be created and fly a distance from the blast face [15].

Three main categories of flyrock are included: cratering, rifling and face bursting. Cratering will occur because of the too small ratio of stemming length to diameter in blasting face. Rifling will happen when stemming material is incompetent or is insignificant. In the third case, which is named face bursting, flyrock may occur due to the production of high-pressure gases in weak rocky plates. Therefore, the explosion near the weak stone plates causes the face bursting state.

According to previous researches, controlled and uncontrolled factors can affect flyrock. The most important 
controllable factors are incompetent stemming, inappropriate burden and spacing, inaccurate drilling, too much explosive energy, inadequate delay timing and unwarranted powder factor $[1,16,17]$. In the case of uncontrollable factors, the most effective factors are related to the rock mass properties.

Several empirical relationships are presented for the prediction of flyrock from the blasting face $[15,18,19]$. These relationships used one or two influential factors, which lead to receive a low-performance prediction of this method. In addition, to increase the safety of the surrounding area, flyrock phenomena must be predicted with higher accuracy level before blasting $[17,20]$. Therefore, to find the flyrock distance, more researches have to be done and models with higher performance prediction have to be presented.

The previous computational techniques developed to predict flyrock distance comprising of artificial neural network (ANN), fuzzy inference system (FIS), Monte Carlo simulation, multiple regression analyses, support vector machine (SVM), rock engineering systems (RES), and adaptive neuro-fuzzy inference system (ANFIS) models [14, 21-24]. According to the above-mentioned methods, providing new ways to predict this phenomenon is necessary.

In engineering sciences, the use of ANNs (as a branch of artificial intelligence) has been highlighted by many investigators [25-31]. Such networks are good tools for forecasting issues, however, they have several limitations such as low learning speed and falling into local minima [32-34]. As mentioned in literatures [20, 23, 35-39], using efficient optimization algorithms (OAs), these limitations can be overcome. Various OAs such as particle swarm optimization (PSO), imperialism competitive algorithm (ICA) and genetic algorithm (GA) can be applied to solve continuous and discontinuous problems. Based on powerful ability of global search of these OAs, weights and biases of an ANN network can be determined to improve its performance prediction. The mentioned hybrid models have been widely-utilized to solve nonlinear and complicated engineering problems.

In this research, to predict flyrock phenomenon, three hybrid intelligent techniques, namely ICA-ANN, GA-ANN and PSO-ANN, are applied. These models were proposed based on the most important parameters influencing flyrock. In the following, after introducing flyrock prediction models and the applied models in this study, some explanations regarding the established database will be given. Then, modelling procedures of the applied techniques are described and finally, the best predictive model will be selected to predict flyrock.

\section{Flyrock empirical methods}

In recent years, many empirical studies have been delivered to predict flyrock in mining engineering. An empirical model was found by Lundborg et al. [19] according to two parameters as follows:

Flyrock $=260 \times D^{2 / 3}$,

$T_{\mathrm{b}}=0.1 \times D^{2 / 3}$,

where $D$ is the hole diameter in inches, and $T_{\mathrm{b}}$ is the size of the fragmented rock in metre.

Raina et al. [40] performed a research according to selected parameters of rock mass and blast design for evaluating the horizontal $\left(\mathrm{FS}_{\mathrm{H}}\right)$ and vertical $\left(\mathrm{FS}_{\mathrm{V}}\right)$ safety factors of flyrock. In another research, the parameters including density, explosive density hole diameter, and confinement state were used by McKenzie [41] for prediction of flyrock and particle (rock) size. A new empirical equation to assess flyrock was used by Trivedi et al. [42]. For the development of this model, 95 explosive data sets were used and an equation based on specific charge, charge concentration, rock strength, burden, stemming length and rock quality designation was proposed to estimate flyrock.

Two power empirical equations were introduced in the study carried out by Marto et al. [23] who developed two high-performance empirical formulations for prediction of flyrock. These results were obtained from 113 operations where each of them contained charge per delay and powder factor. Furthermore, Jahed Armaghani et al. [14] presented an empirical technique for predicting flyrock. This technique was based on graph shown for different values of maximum charge per delay in a range of $(75-550 \mathrm{~kg})$ and also for various powder factor values in a range of $\left(0.5-1.1 \mathrm{~kg} / \mathrm{m}^{3}\right)$.

\section{Intelligent techniques}

\subsection{Artificial neural networks}

Due to a structure of the human brain, artificial neural network (ANN) [43] can be created and developed to process information. The ANN structure consists of three main parts: input, hidden and output layers. In each network layer, the binding elements, namely neurons, transmit data from one layer to the next. Due to the strengthening or weakening of this transfer, the weights in each network control this transfer. To calculate the output of each layer's neuron, an activation function of linear or sigmoid should be used. The number of used neurons in each layer is specified by the total number of inputs. Usually, the number of neurons can be obtained using a complex way or trial and error procedure. 
Among available network training algorithms, the back propagation (BP) training algorithm is more common in engineering sciences [44-46]. Briefly, two main parts of the ANN modelling are creation of a network construction and the relevant weights determination. Based on minimization error values, the network weights are adjusted by BP training algorithm. The values obtained at each stage are compared with the desired output values. If the errors are not desirable, the process should be continued to get desired values and reduce the system error [46-48].

\subsection{Genetic algorithm}

Genetic algorithm (GA), which was first developed by Holland [49], is one of the well-established optimization methods. This OA is inspired by the theory of natural selection. This method were expanded by Goldberg [50]. GA has been widely-performed to optimize various problems in engineering and science. One of the main advantages of this algorithm is its ability to solve complex and highly nonlinear problems. For optimization purposes, such as linear or non-linear, static or dynamic (change with time), continuous or discontinuous or contain a random noise, GA can be used to solve. In addition, GA is considered as a problematic algorithm due to its limitations such as determining various parameters of the algorithm (population size and genetic operator rates) and creating the proper function. To determine these values, the designer should be very careful while they will affect the convergence of the algorithm and also its results [51, 52]. In GA, chromosomes have a fixed length that encodes issues to linear binary strings between 0 and 1 . These chromosomes cause production of generation. As shown in Fig. 1, the chromosome is selected as a random characteristics and based on these characteristics, chromosomes are evaluated. Then, they are selected using genetic operators of the remaining chromosomes and start generating new generations. Crossover chooses between parents and mutation works in a range of $0-1$. This process is repeated until creation of the best generations evaluated based on their performance [53, 54].

\subsection{Particle swarm optimization}

Another OA used in this study is particle swarm optimization (PSO) which was developed by Kennedy and Eberhart [55]. PSO is inspired by cumulative behaviour of particles. Among all advantages of PSO, a high learning speed and using less memory compared to GA should be noted. In PSO, to find the best position, a swarm of particles searches the best personal $\left(p_{\text {best }}\right)$ and the best global $\left(g_{\text {best }}\right)$ positions [35]. In other hands, in each system iteration, the particle moves toward finding the best positions ( $p_{\text {best }}$ and $\left.g_{\text {best }}\right)$. The velocity and position of particles are obtained as follows:

$V_{\text {new }}=w \times V+C_{1} \cdot r_{1}\left(p_{\text {best }}-X\right)+C_{2} \cdot r_{2}\left(g_{\text {best }}-X\right)$,
Fig. 1 GA algorithm

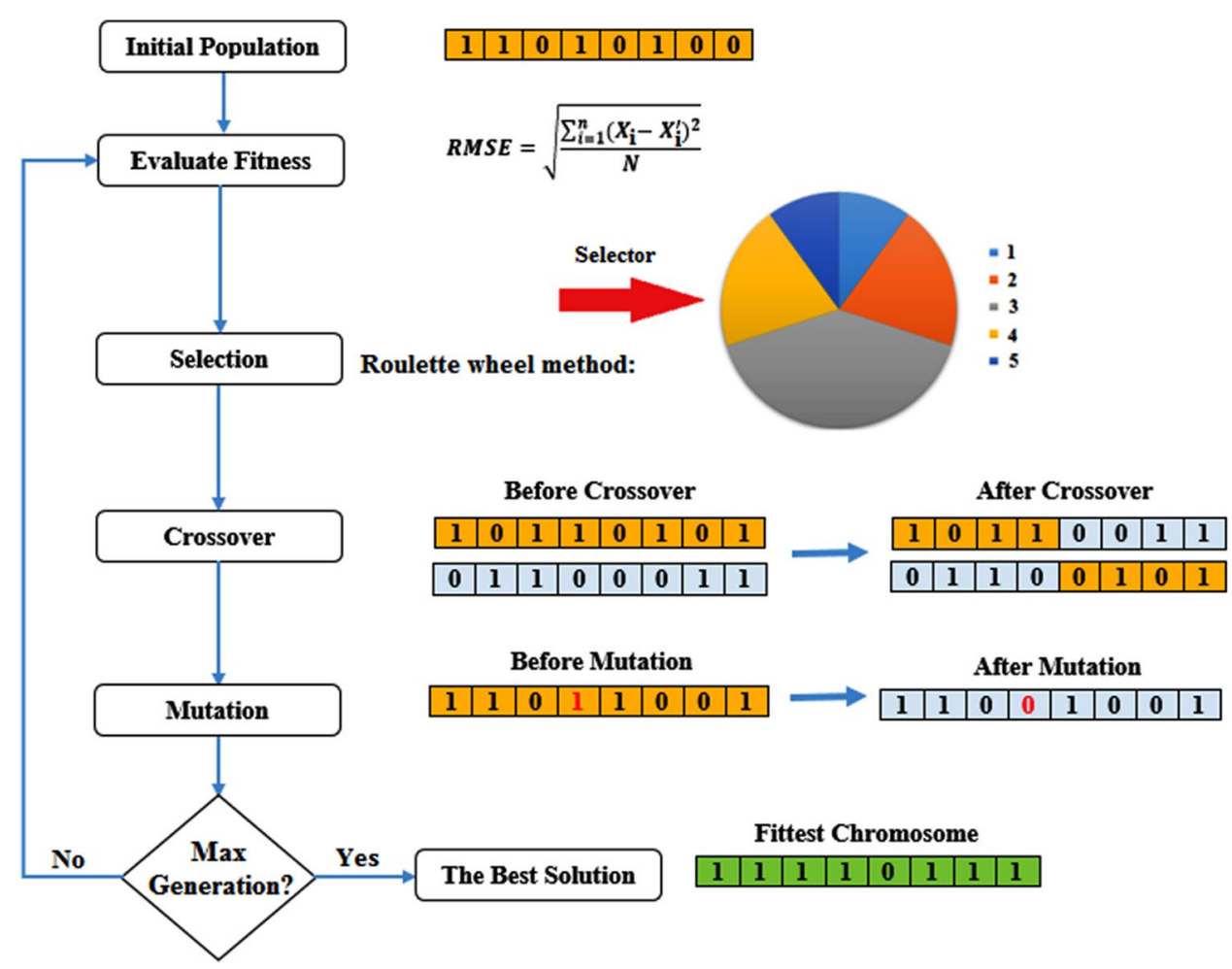


$X_{\text {new }}=X+V_{\text {new }}$,

where $V$ and $X$ denote current velocity and position of particle, respectively, $C_{1}$ and $C_{2}$ are two positive acceleration constants, $V_{\text {new }}$ and $X_{\text {new }}$ denote new velocity and position of particle, respectively, $w$ denotes the inertial weight, and $r_{1}$ and $r_{2}$ represent the random numbers in $(0,1)$. More information about the PSO algorithm description/implementation can be found in the other researches [45, 56]. Furthermore, Fig. 2 shows details of a PSO algorithm.

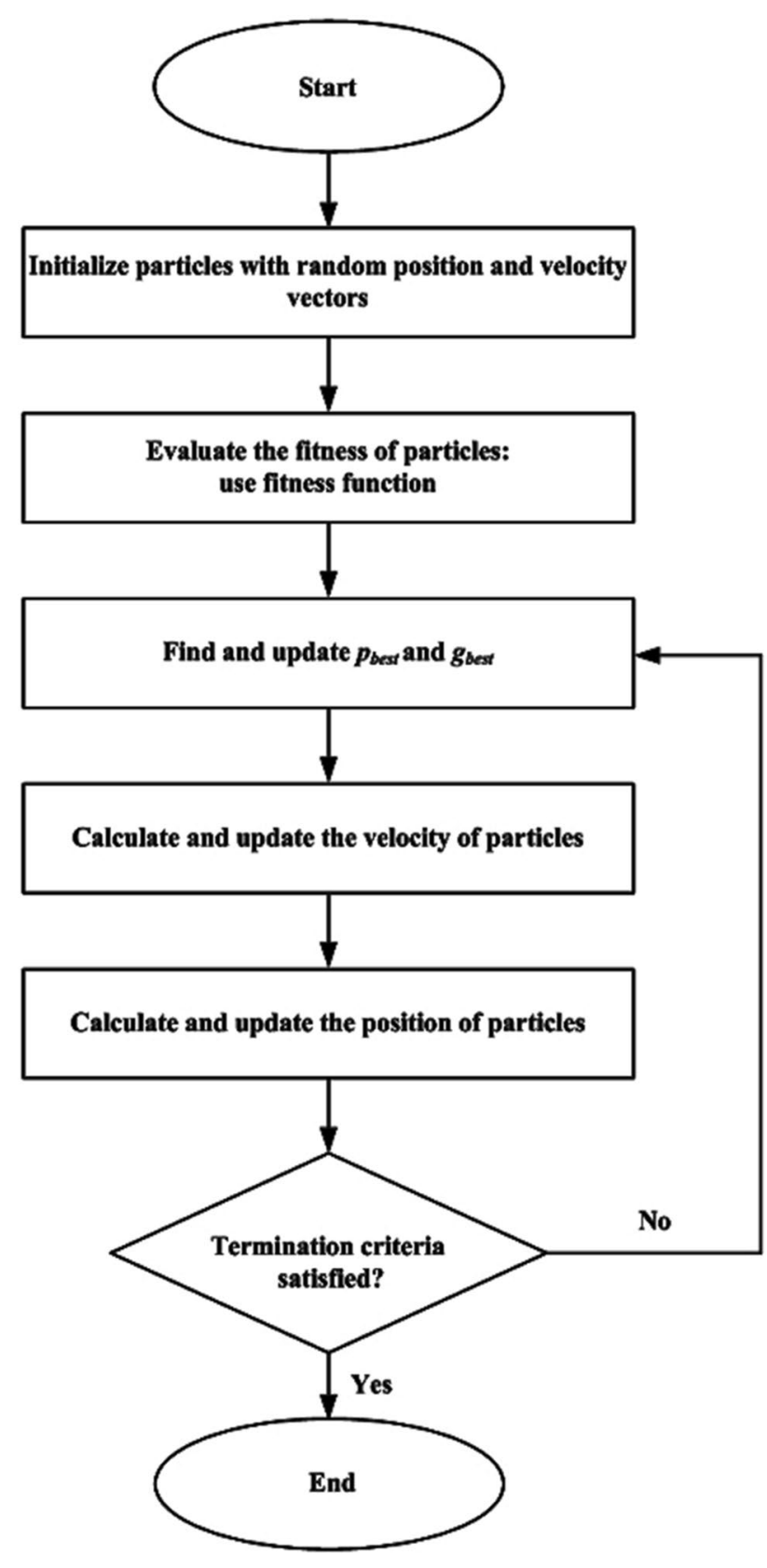

Fig. 2 PSO algorithm

\subsection{Imperialist competitive algorithm}

Imperialist competitive algorithm (ICA) was first introduced and developed by Atashpaz-Gargari and Lucas [57] as a global search population-based on optimization problems. The beginning of ICA is with a production of randomly initial population called countries. The process continues to generate $N$ number of countries $\left(N_{\text {country }}\right)$, and then the number of imperialists, i.e. $N_{\text {imp }}$ should be selected as a specific number of the countries which have the lowest costs. The remaining countries $\left(N_{\mathrm{col}}\right)$ are used as special functions (functions of the imperialist normalized costs) among other empires. In this algorithm, imperialists are more powerful when they have more colonies. Three operators including assimilation, revolution and competition are the main parts of ICA [58, 59]. The part of ICA body is related to colonies that are equally absorbed by the imperialists. However, the revolution is causing many sudden changes. In the competition part, the imperialists are struggling to get more colonies, and in this competition, any empire that can achieve the desired criteria eventually wins. This process is repeated until the end of the desired benchmark. The number of decades in ICA has similar process of the number of generations in GA and the number of particles in PSO. To design them, evaluating in results of root mean square (RMSE) can be useful. More information/facts about ICA are available in several researches $[33,57,60]$. Figure 3 shows a structure of ICA algorithm.

\subsection{Hybrid algorithms}

In engineering applications, many research have been carried out to enhance the ability of ANN models through OAs such as GA, PSO and ICA (e.g. [51, 61-65]). Due to the weakness of BP in finding the accurate global minimum, the ANN model may achieve undesirable results [66]. Nevertheless, the ANN model is more likely to be caught up in local minima, while OAs by setting weights and biases of ANN could solve the mentioned ANN problem. In this study, three methods of hybrid systems, i.e. ICA-ANN, GA-ANN and PSO-ANN are constructed to predict SF of the slopes under static and dynamic conditions. In the created systems, ICA, GA and PSO search for global minimum, and then ANN selected it for achieving the best system results.

\section{Studied quarry sites and data collection}

Data were collected to predict flyrock from six granite quarry mines in Johor state, Malaysia. Their names are Taman Bestari with latitude of $1^{\circ} 60^{\prime} 41^{\prime \prime} \mathrm{N}$ and longitude of $103^{\circ} 78^{\prime} 32^{\prime \prime} \mathrm{E}$, Ulu Tiram with latitude of $1^{\circ} 36^{\prime} 41^{\prime \prime} \mathrm{N}$ and longitude of $103^{\circ} 49^{\prime} 20^{\prime \prime} \mathrm{E}$, Trans Crete with latitude 


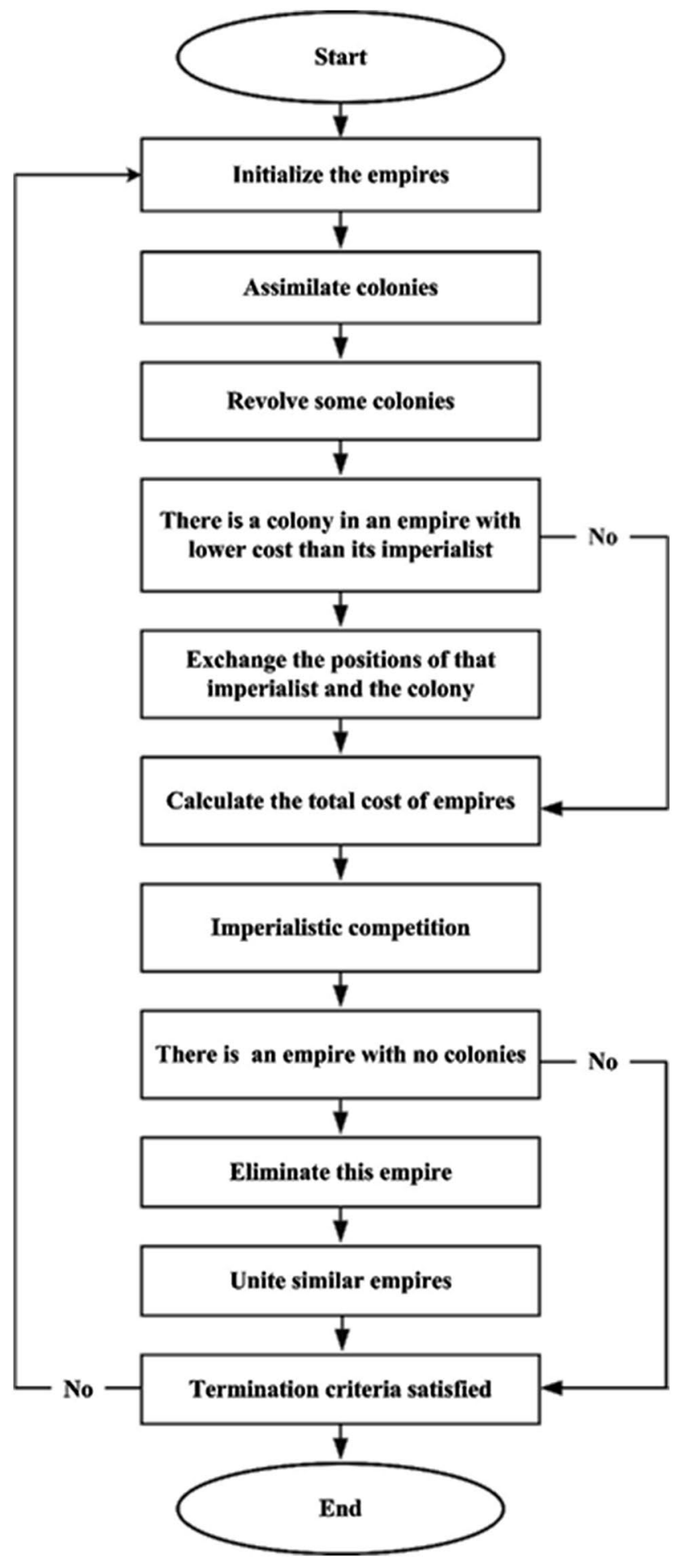

Fig. 3 ICA algorithm

of $1^{\circ} 31^{\prime} 21^{\prime \prime} \mathrm{N}$ and longitude of $103^{\circ} 52^{\prime} 60^{\prime \prime} \mathrm{E}$, Putri Wangsa with latitude of $1^{\circ} 35^{\prime} 32^{\prime \prime} \mathrm{N}$ and longitude of $103^{\circ} 48^{\prime} 4^{\prime \prime} \mathrm{E}$, Ulu Choh with latitude of $1^{\circ} 31^{\prime} 48^{\prime \prime} \mathrm{N}$ and longitude of $103^{\circ} 32^{\prime} 41^{\prime \prime} \mathrm{E}$ and Masai with latitude of $1^{\circ} 29^{\prime} 42^{\prime \prime} \mathrm{N}$ and longitude of $103^{\circ} 52^{\prime} 28^{\prime \prime} \mathrm{E}$. The target of explosions is to produce $8000-24,000$ tons per month. The number of explosive operations in these sites is varied from 6 to 15 . In the studied sections, the rock quality designation (RQD) and the values recorded by Schmidt hammer are $25-55 \%$ and 17-42, respectively. Figure 4 shows a view of Ulu Tiramstudied quarry.

In the mentioned sites, flyrock phenomenon was considered as one of the most important environmental issues. 262 sets of blasting data were collected where, in each of them, data are included: burden to spacing ratio, blast-hole diameter, powder factor, stemming length, the maximum charge per delay, and blast-hole depth as inputs and flyrock distance as output. For blast operations, ammonium nitrate and fuel oil (ANFO) was used as explosive. In these operations, blasthole diameters of 75, 89, 115 and $150 \mathrm{~mm}$ were utilized. The values of powder factor and stemming length have ranges of $0.44-1.14 \mathrm{~kg} / \mathrm{m}^{3}$ and 1.4 and $4.5 \mathrm{~m}$, respectively.

For recording the maximum flyrock, two video cameras were used. To measure the distance of flyrocks, blasting benches were coloured, and using the mentioned cameras, the flyrocks could be seen separately after the operations. Then, the maximum horizontal distance of fragments was considered as the maximum flyrock distance. It should be noted that the data used in this study have been previously utilized by Shirani et al. [67]. Methods of data collection were used similar to previous researchers [2, 5, 15, 33, 40]. So, more information regarding parameters used in this study can be found in the mentioned study.

\section{Model development}

In this section, descriptions of implementing hybrid models, namely ICA-ANN, PSO-ANN and GA-ANN, in predicting flyrock distance are presented. Effective parameters on ICA, PSO and GA are determined and used to receive higher accuracy level for flyrock prediction.

\subsection{ICA-ANN}

To obtain the best ICA-ANN model, its important factors/ parameters should be investigated. Prior to investigation of ICA parameters, ANN architecture should be determined. This was accomplished by considering a trial and error process and it was found that an architecture of $6 \times$ $9 \times 1$ (or a model with nine hidden neurons) receives better results. Therefore, the mentioned architecture was used for all hybrid intelligent systems in this study. As mentioned earlier, $N_{\text {country }}, N_{\text {decade }}$, and $N_{\text {imp }}$ are considered as the most influential parameters on ICA. To determine $N_{\text {imp }}$, many models were designed using different values of $N_{\text {imp }}$, i.e., $5,10,15,20,25$ and 30 . In these models, $N_{\text {country }}=300$ 
Fig. 4 A view of Ulu Tiramstudied quarry

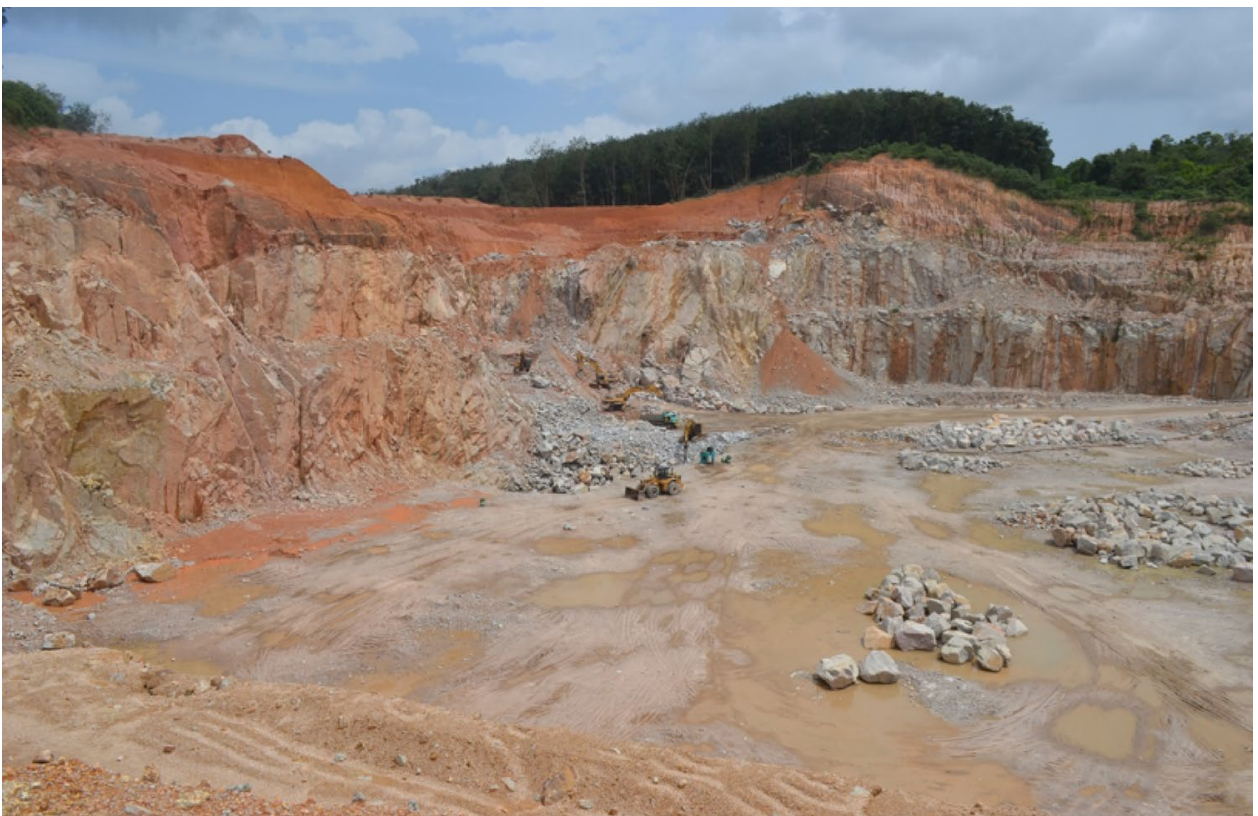

and $N_{\text {decade }}=100$ were utilized. Results of this parametric study showed that $N_{\text {imp }}=5$ can obtain higher performance system capacity. To select the best value for $N_{\text {decade }}$, as displayed in Fig. 5, various models with $N_{\text {country }}$ values of 50 , 100, 150, 200, 250, 300, 350 and 400 were constructed and evaluated based on their RMSE. As a result, RMSE results are not changed after $N_{\text {decade }}$ equal to 500. In the last step of modelling, using $N_{\text {imp }}=5$ and $N_{\text {decade }}=500$, a various number of countries were considered and their ICA-ANN models were built. These models were evaluated based on performance indices (PIs), i.e., coefficient of determination $\left(R^{2}\right)$ and RMSE values as presented in Table 1. A ranking method introduced by Zorlu et al. [68] was used to choose the best hybrid models in this study.

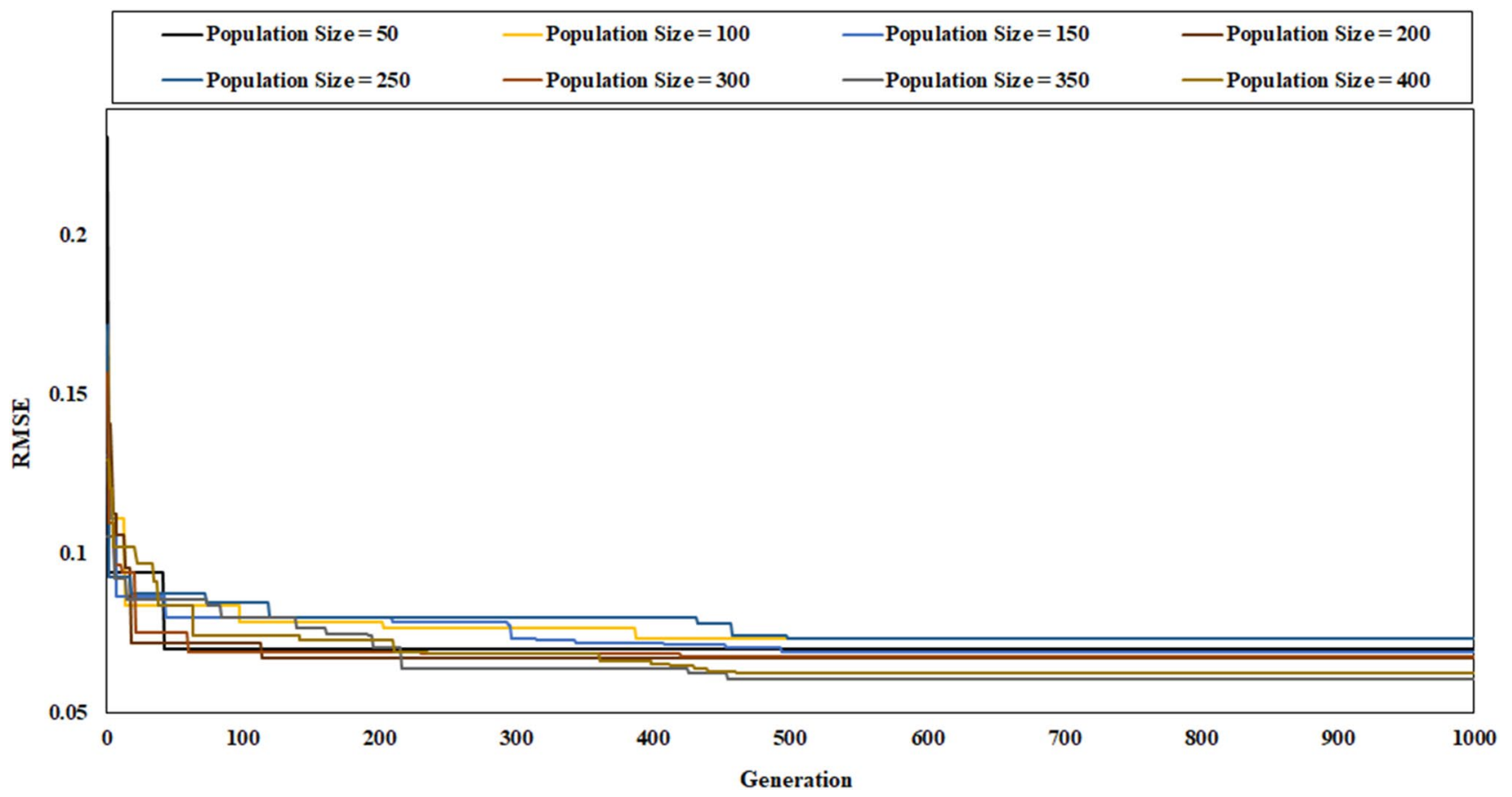

Fig. 5 ICA-ANN models with various $N_{\text {country }}$ values 
Table 1 Different $N_{\text {country }}$ effects in estimating flyrock distance

\begin{tabular}{|c|c|c|c|c|c|c|c|c|c|c|}
\hline \multirow[t]{3}{*}{ Model No. } & \multirow[t]{3}{*}{$N_{\text {country }}$} & \multicolumn{4}{|c|}{ Network Result } & \multicolumn{4}{|c|}{ Ranking } & \multirow[t]{3}{*}{ Total rank } \\
\hline & & \multicolumn{2}{|l|}{ TR } & \multicolumn{2}{|l|}{ TS } & \multicolumn{2}{|l|}{$\mathrm{TR}$} & \multicolumn{2}{|c|}{ TS } & \\
\hline & & $\overline{R^{2}}$ & $\overline{\text { RMSE }}$ & $\overline{R^{2}}$ & $\overline{\mathrm{RMSE}}$ & $\overline{R^{2}}$ & $\overline{\text { RMSE }}$ & $\overline{R^{2}}$ & $\overline{\text { RMSE }}$ & \\
\hline 1 & 50 & 0.923 & 0.063 & 0.782 & 0.079 & 2 & 3 & 2 & 2 & 9 \\
\hline 2 & 100 & 0.938 & 0.053 & 0.934 & 0.059 & 3 & 5 & 7 & 5 & 20 \\
\hline 3 & 150 & 0.945 & 0.051 & 0.920 & 0.059 & 6 & 7 & 4 & 5 & 22 \\
\hline 4 & 200 & 0.938 & 0.055 & 0.923 & 0.057 & 3 & 4 & 5 & 6 & 18 \\
\hline 5 & 250 & 0.942 & 0.051 & 0.934 & 0.060 & 4 & 7 & 7 & 4 & 22 \\
\hline 6 & 300 & 0.943 & 0.052 & 0.958 & 0.045 & 5 & 6 & 8 & 8 & 27 \\
\hline 7 & 350 & 0.953 & 0.047 & 0.915 & 0.061 & 8 & 8 & 3 & 3 & 22 \\
\hline 8 & 400 & 0.947 & 0.052 & 0.933 & 0.046 & 7 & 6 & 6 & 7 & 26 \\
\hline
\end{tabular}

$T R$ training, $T S$ testing
A complete version of this technique can be found in Zorlu et al. [68] and according to it, a rank value was assigned for each PI in its group (training and testing). For example, values of $0.923,0.938,0.945,0.938,0.942,0.943$, 0.953 and 0.947 were achieved for $R^{2}$ of training datasets of models $1-8$, respectively, and values of $2,3,6,3,4,5,8$ and 7 were assigned for their ranks, respectively. This has accomplished for RMSE results as well. Then, a summation value of rating of $R^{2}$ train, RMSE train, $R^{2}$ test and RMSE test was calculated and assigned to each model and, based on them, model $6\left(N_{\text {country }}=300\right)$ with total rank of 27 is the best ICA-ANN model. Evaluation of the best ICA-ANN result will be given later. It should be noted that all models were built using $80 \%$ of whole data as training and $20 \%$ of them as testing.

\subsection{PSO-ANN}

As pointed out before, several parameters such as coefficients of velocity equation, number of particle, number of iteration and inertia weight have a deep impact on PSO algorithm. According to literatures [55, 69], coefficients of velocity equation equal to 2 and inertia weight of 0.25 showed an acceptable results in other implemented PSO works. Therefore, these values were used in all PSO-ANN models. To select the best value for number of iteration, as displayed in Fig. 6, various models with swarm size values

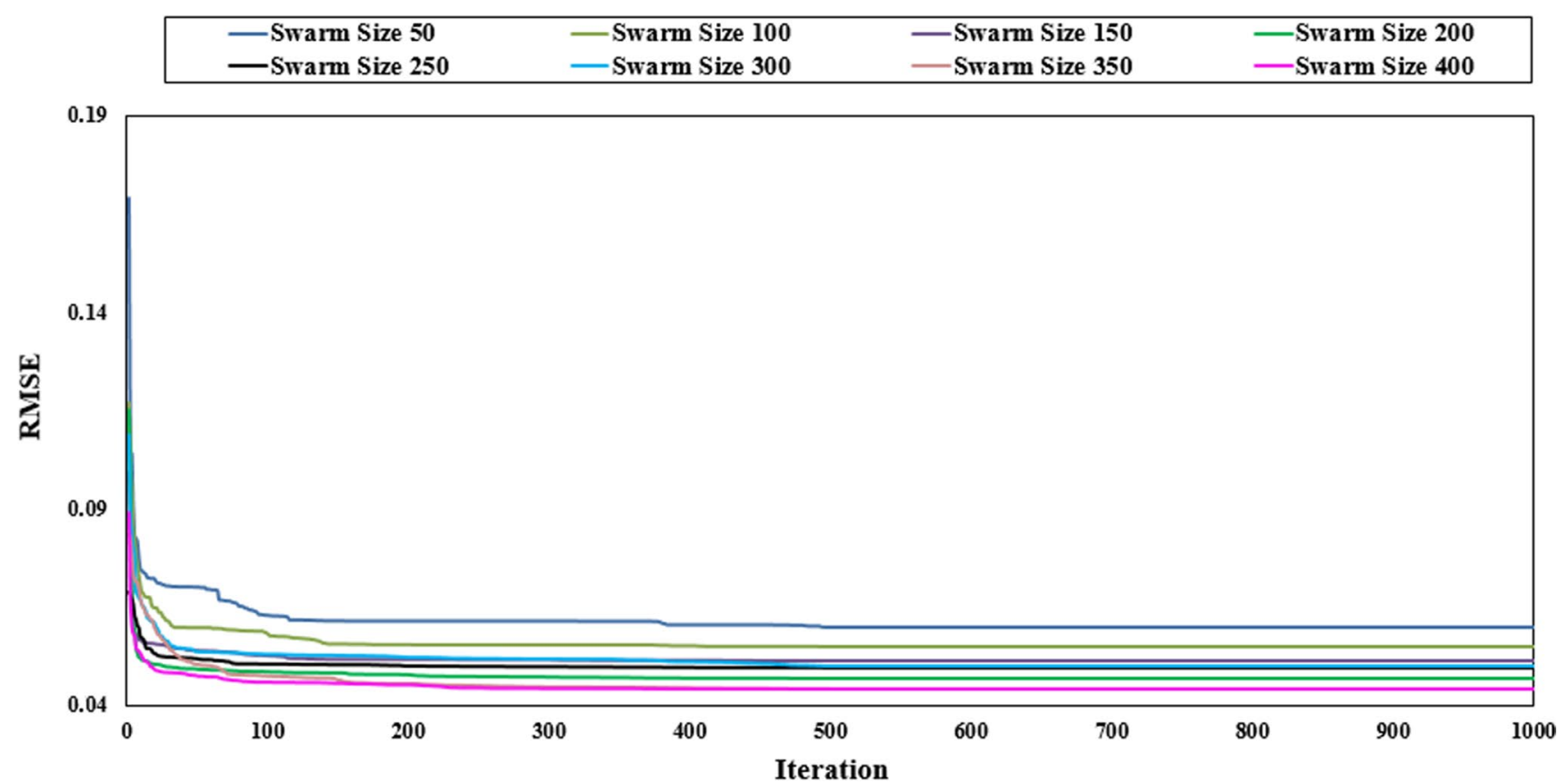

Fig. 6 PSO-ANN models with various swarm sizes 
Table 2 Different swarm size in estimating flyrock distance

\begin{tabular}{|c|c|c|c|c|c|c|c|c|c|c|}
\hline \multirow[t]{3}{*}{ Model no. } & \multirow[t]{3}{*}{ Swarm size } & \multicolumn{4}{|c|}{ Network result } & \multicolumn{4}{|c|}{ Ranking } & \multirow[t]{3}{*}{ Total rank } \\
\hline & & \multicolumn{2}{|l|}{ TR } & \multicolumn{2}{|l|}{$\mathrm{TS}$} & \multicolumn{2}{|l|}{ TR } & \multicolumn{2}{|c|}{$\mathrm{TS}$} & \\
\hline & & $\overline{R^{2}}$ & $\overline{\text { RMSE }}$ & $\overline{R^{2}}$ & $\overline{\text { RMSE }}$ & $\overline{R^{2}}$ & $\overline{\text { RMSE }}$ & $\overline{R^{2}}$ & $\overline{\text { RMSE }}$ & \\
\hline 1 & 50 & 0.926 & 0.060 & 0.937 & 0.052 & 1 & 2 & 4 & 4 & 11 \\
\hline 2 & 100 & 0.940 & 0.055 & 0.902 & 0.059 & 2 & 3 & 1 & 3 & 9 \\
\hline 3 & 150 & 0.949 & 0.052 & 0.932 & 0.044 & 4 & 4 & 3 & 7 & 18 \\
\hline 4 & 200 & 0.953 & 0.047 & 0.956 & 0.044 & 6 & 6 & 7 & 7 & 26 \\
\hline 5 & 250 & 0.946 & 0.050 & 0.955 & 0.049 & 3 & 5 & 6 & 6 & 20 \\
\hline 6 & 300 & 0.951 & 0.050 & 0.944 & 0.040 & 5 & 5 & 5 & 8 & 23 \\
\hline 7 & 350 & 0.958 & 0.045 & 0.959 & 0.044 & 7 & 7 & 8 & 7 & 29 \\
\hline 8 & 400 & 0.961 & 0.044 & 0.924 & 0.051 & 8 & 8 & 2 & 5 & 23 \\
\hline
\end{tabular}

$T R$ training, $T S$ testing of 50,100,150,200, 250, 300, 350 and 400 were built and evaluated based on their RMSE. As a result, RMSE results are not changed after swarm size of 500 for all models. To identify the optimum value for swarm size, a total number of eight PSO-ANN models were constructed to predict flyrock distance as tabulated in Table 2. Similar to previous section, ranking system proposed by Zorlu et al. [68] was performed and based on total rank values (Table 2), model 7 with swarm size of 350 and total rank of 29 shows the best system results. For this model, $R^{2}$ of 0.958 and 0.959 were obtained for training and testing datasets, respectively. Evaluation of the selected PSO-ANN model will be discussed later.

\subsection{GA-ANN}

As stated earlier, to design a GA-ANN model, influence of the effective GA factors should be investigated. Mutation probability values, percentage of recombination were set as 25 , and $9 \%$, respectively. As a cross-over operation, a single point with $70 \%$ possibility is used. A parametric study was conducted for determination of the maximum number of generation $\left(G_{\max }\right)$ effects on network performance. To obtain the best $G_{\max }$, as shown in Fig. 7, a value of 1000 generation was assigned as stopping criteria considering RMSE values. As a result, like two previous

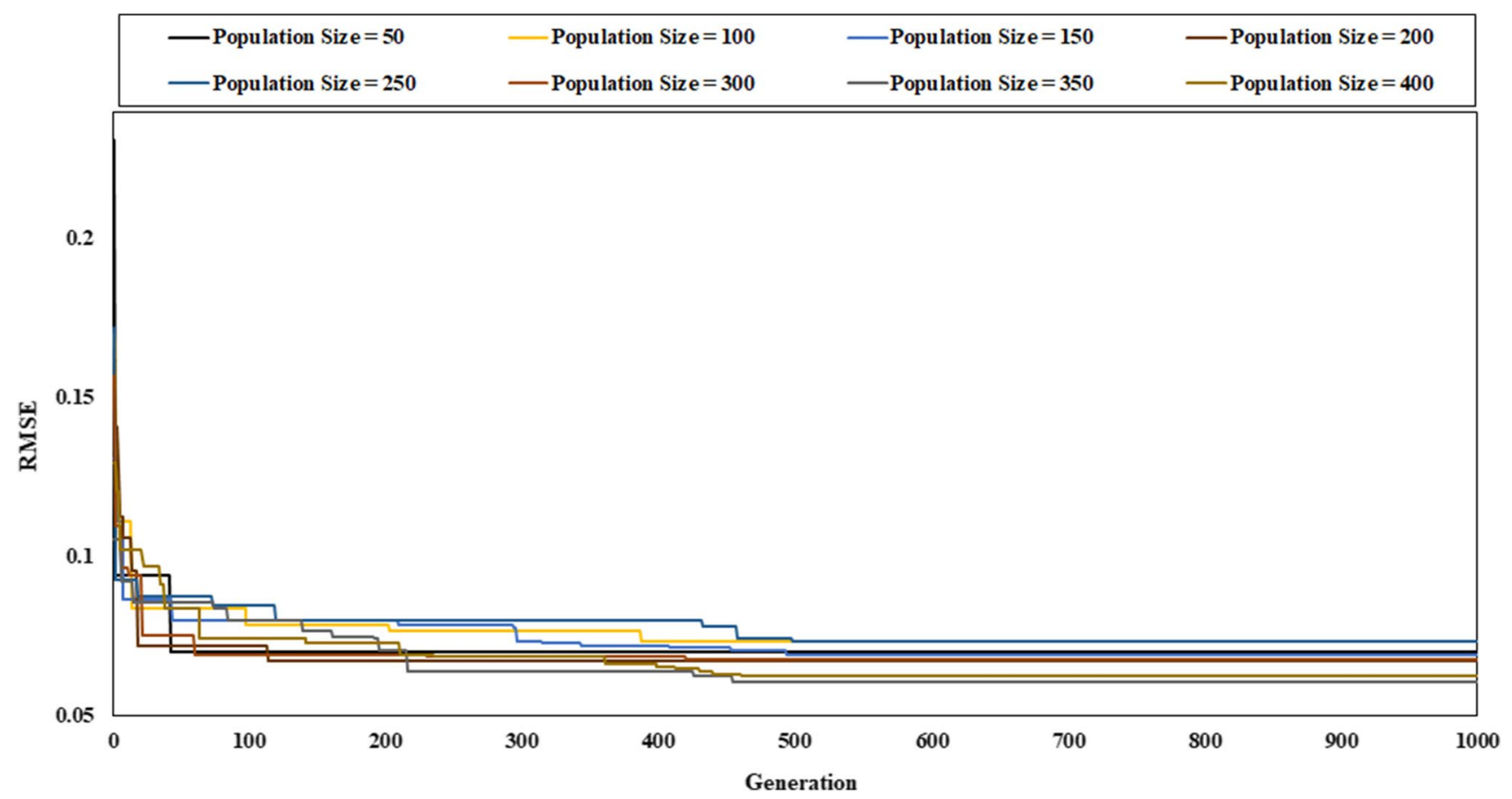

Fig. 7 GA-ANN models with various population sizes 
Table 3 Different population size in estimating flyrock distance

\begin{tabular}{|c|c|c|c|c|c|c|c|c|c|c|}
\hline \multirow[t]{3}{*}{ Model no. } & \multirow[t]{3}{*}{ Swarm size } & \multicolumn{4}{|c|}{ Network Result } & \multicolumn{4}{|c|}{ Ranking } & \multirow[t]{3}{*}{ Total rank } \\
\hline & & \multicolumn{2}{|l|}{$\mathrm{TR}$} & \multicolumn{2}{|l|}{$\mathrm{TS}$} & \multicolumn{2}{|l|}{ TR } & \multicolumn{2}{|c|}{$\mathrm{TS}$} & \\
\hline & & $\overline{R^{2}}$ & $\overline{\text { RMSE }}$ & $\overline{R^{2}}$ & $\overline{\text { RMSE }}$ & $\overline{R^{2}}$ & $\overline{\text { RMSE }}$ & $\overline{R^{2}}$ & $\overline{\text { RMSE }}$ & \\
\hline 1 & 50 & 0.904 & 0.069 & 0.842 & 0.075 & 5 & 3 & 1 & 1 & 10 \\
\hline 2 & 100 & 0.894 & 0.073 & 0.867 & 0.069 & 3 & 1 & 2 & 3 & 9 \\
\hline 3 & 150 & 0.902 & 0.068 & 0.892 & 0.070 & 4 & 4 & 3 & 2 & 13 \\
\hline 4 & 200 & 0.907 & 0.067 & 0.897 & 0.068 & 6 & 5 & 4 & 4 & 19 \\
\hline 5 & 250 & 0.891 & 0.072 & 0.916 & 0.062 & 2 & 2 & 5 & 5 & 14 \\
\hline 6 & 300 & 0.907 & 0.066 & 0.948 & 0.048 & 6 & 6 & 8 & 8 & 28 \\
\hline 7 & 350 & 0.930 & 0.057 & 0.932 & 0.058 & 8 & 8 & 7 & 7 & 30 \\
\hline 8 & 400 & 0.917 & 0.062 & 0.922 & 0.060 & 7 & 7 & 6 & 6 & 26 \\
\hline
\end{tabular}

TR training, TS testing
Table 4 Results of the selected hybrid models in predicting flyrock distance

\begin{tabular}{llllll}
\hline Model & \multicolumn{2}{l}{ Training } & & \multicolumn{2}{l}{ Testing } \\
\cline { 2 - 3 } \cline { 5 - 6 } & $R^{2}$ & RMSE & & $R^{2}$ & RMSE \\
\hline ICA-ANN & 0.943 & 0.052 & 0.958 & 0.045 \\
PSO-ANN & 0.958 & 0.045 & 0.959 & 0.044 \\
GA-ANN & 0.930 & 0.057 & 0.932 & 0.058 \\
\hline
\end{tabular}

hybrid models, after generation No. 500, the network performance is unchanged. Therefore, the optimum generation No. 500 was used in this study. In the final step, a series of hybrid GA-ANN models (Table 3) were created to determine the best population size (among size values of 50, 100, 150, 200, 250, 300, 350 and 400). Results showed that population size of 350 with total rank of 30 can provide higher performance prediction in terms of both $R^{2}$ and RMSE indices. The obtained results of model number 5 (the best one) will be discussed in detail later.

\section{Results and discussion}

Prediction of flyrock distance due to blasting is the aim of the present study. Hence, the most influential parameters on flyrock were identified and used. Three hybrid intelligent systems, namely ICA-ANN, PSO-ANN and GA-ANN were applied to select the best predictive flyrock model among them. Many hybrid models were constructed for each predictive technique and the best of them was chosen. Results of the selected models of ICA-ANN, PSO-ANN and GA-ANN based on RMSE and $\mathrm{R}^{2}$ indices in predicting flyrock are presented in Table 4. Equations of RMSE and $\mathrm{R}^{2}$ can be found in other studies [70, 71]. High performances of the training datasets prove that the learning process of these predictive models is successful.
While, a high accuracy level of testing datasets shows that the developed model is well-generalized. Although all predictive models are capable to predict flyrock, as a result, PSO-ANN predictive model can provide higher performance capacity in terms of $R^{2}$ values of both training and testing phases. Additionally, RMSE values of $(0.052$, 0.045 and 0.057$)$ and $(0.045,0.044$ and 0.058$)$ were achieved for training and testing of ICA-ANN, PSO-ANN and GA-ANN predictive models, respectively. These results indicated that lower system error can be obtained by developing PSO-ANN model among all implemented models. Predicted flyrock values together with their actual values for ICA-ANN, PSO-ANN and GA-ANN predictive models are displayed in Figs. 8, 9 and 10, respectively. In these figures, predicted results are presented for both training and testing datasets. According to these figures, although all models have acceptable prediction capacity in prediction flyrock distance, PSO-ANN model can introduce as a new hybrid model in this field.

It is worth mentioning that the same data used in this study have been utilized by Shirani et al. [67]. They developed and introduced a genetic programming (GP) model with $R^{2}$ values of 0.908 and 0.819 for training and testing datasets, respectively. Comparing their results with the results obtained from this study revealed that all developed hybrid predictive models can apply better than GP model for the same database and could introduce as trustable models in the field of blasting operations.

\section{Sensitivity analysis}

A sensitivity analysis was performed on the data to determine the impact of each data on the output. Therefore, the method introduced by Yang and Zang in this study was used. All data pairs were utilized to construct a data array $X$ as follows:

$X=\left\{x_{1}, x_{2}, x_{3}, \ldots x_{i}, \ldots, x_{n}\right\}$. 


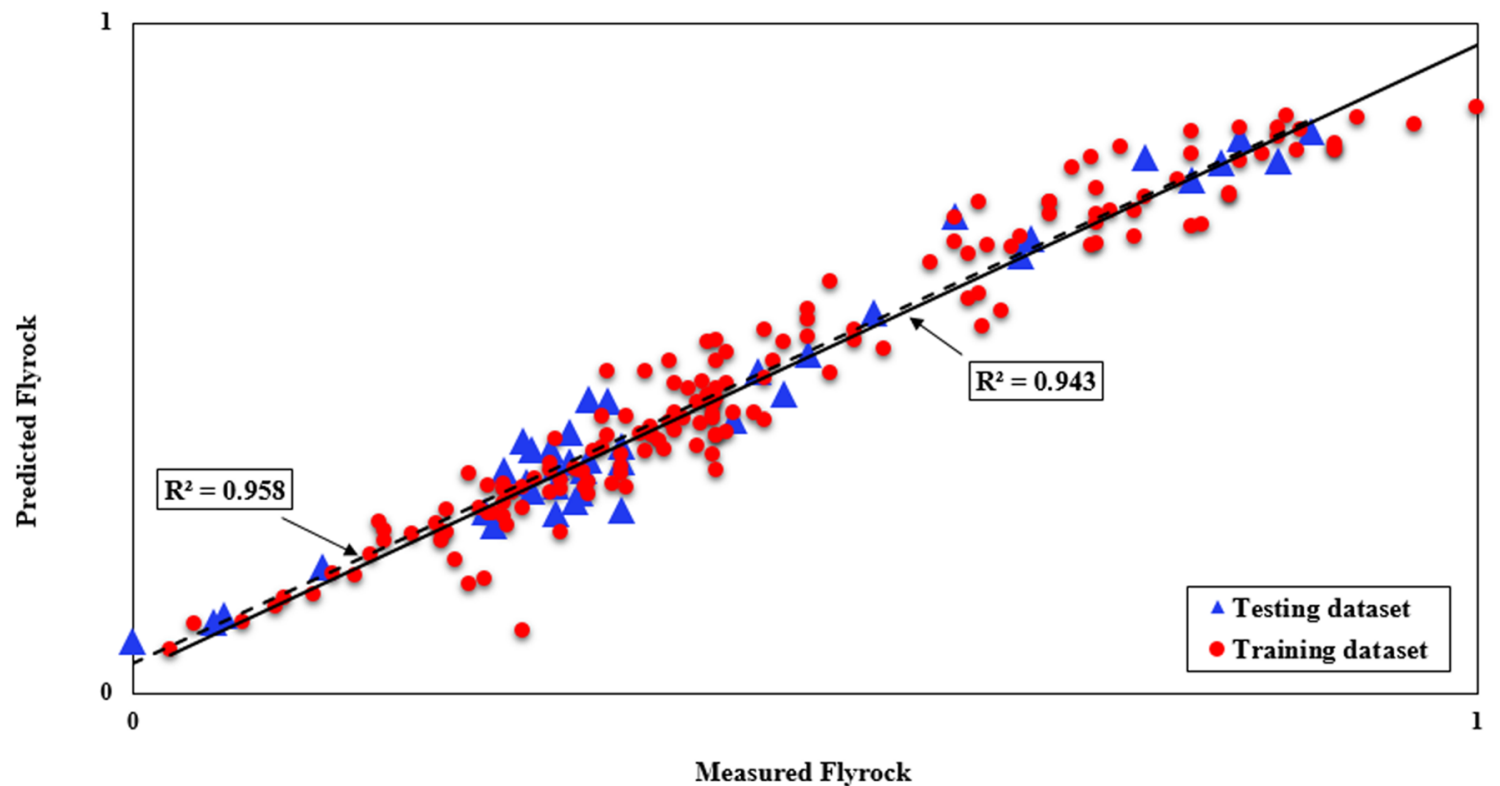

Fig. 8 Results of ICA-ANN model in estimating flyrock

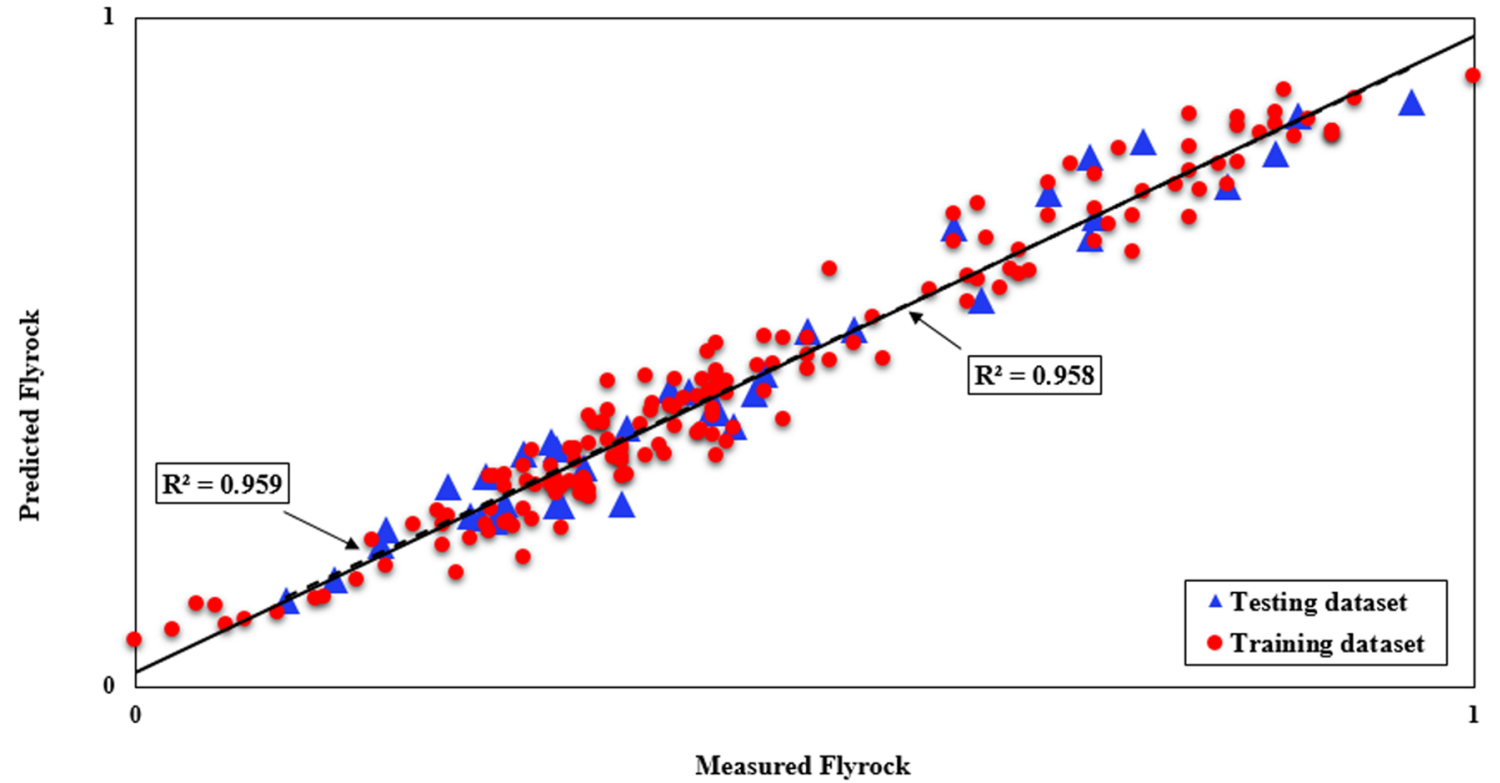

Fig. 9 Results of PSO-ANN model in estimating flyrock

Variable $x_{i}$ in array $X$ is a length vector of $m$ as:

$x_{i}=\left\{x_{i 1}, x_{i 2}, x_{i 3}, \ldots x_{i m}\right\}$.

The strength of the relationship $\left(r_{i j}\right)$ between datasets $X_{i}$ and $X_{j}$ can be expressed as follows:

$r_{i j}=\frac{\sum_{k=1}^{m} x_{i k} x_{j k}}{\sqrt{\sum_{k=1}^{m} x_{i k}^{2} \sum_{k=1}^{m} x_{i k}^{2}}}$.
Figure 11 shows the relationship between input data and output. As can be seen, among all data, the hole diameter and hole depth have the highest and lowest relation with the output, respectively. 


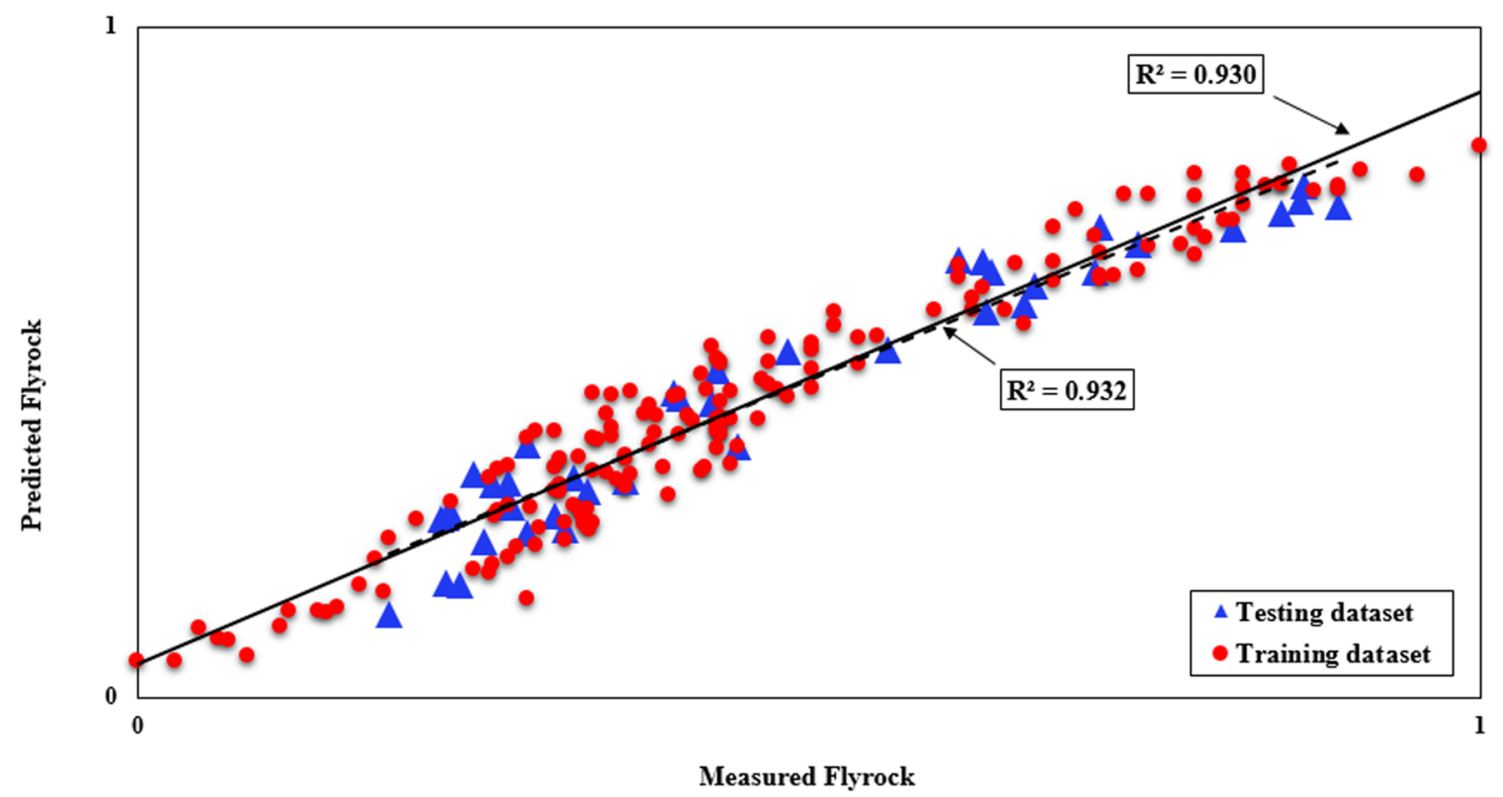

Fig. 10 Results of GA-ANN model in estimating flyrock

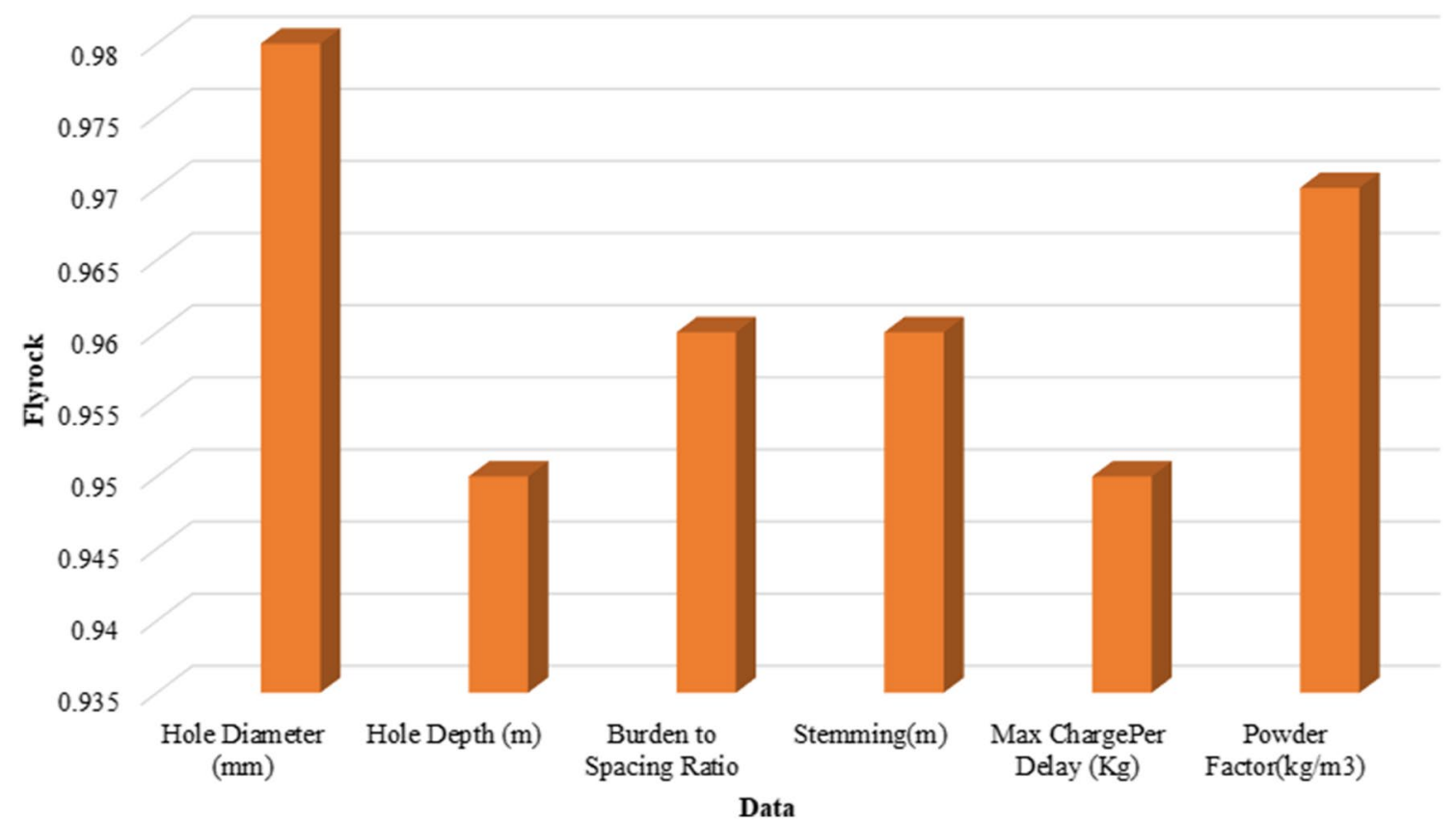

Fig. 11 Sensitivity analysis to determine the impact of each data on the output

\section{Conclusions}

In this study, three hybrid models, i.e., ICA-ANN, PSO-ANN and GA-ANN were considered and developed to predict flyrock. To achieve this aim, the most influential parameters on OAs, i.e., ICA, PSO and GA, were identified based on background of these techniques and also available literatures. Then, these parameters were carefully designed using several rounds of parametric studies. At the end of each model designing, eight models were constructed and their related results were achieved based on RMSE and $R^{2}$. In this step, evaluation of the obtained results was performed using the ranking technique and it was found that all hybrid models can offer a high level of accuracy in estimating 
flyrock distance. Nevertheless, a slightly higher performance prediction (lower error and higher coefficient of determination) was observed when a PSO-ANN model is developed. RMSE values of $(0.052,0.045$ and 0.057$)$ and $(0.045,0.044$ and 0.058 ) were found for training and testing of ICA-ANN, PSO-ANN and GA-ANN predictive models, respectively, which show higher efficiency of the PSO-ANN model compared to other implemented models. Furthermore, in terms of $R^{2}$, a similar trend was obtained. It can be concluded that if a predictive model with lowest error is needed, a hybrid PSO-ANN model is introduced as a superior one to predict flyrock distance. Additionally, results of sensitivity analysis showed that the effect of hole diameter on flyrock is slightly higher than the effect of others.

\section{Compliance with ethical standards}

Conflict of interest The authors declare no conflict of interest.

Open Access This article is distributed under the terms of the Creative Commons Attribution 4.0 International License (http://creativeco mmons.org/licenses/by/4.0/), which permits unrestricted use, distribution, and reproduction in any medium, provided you give appropriate credit to the original author(s) and the source, provide a link to the Creative Commons license, and indicate if changes were made.

\section{References}

1. Bhandari S (1997) Engineering rock blasting operations. A A Balkema, p 388

2. Khandelwal M, Singh TN (2005) Prediction of blast induced air overpressure in opencast mine. Noise Vib Worldw 36:7-16

3. Verma AK, Singh TN (2011) Intelligent systems for ground vibration measurement: a comparative study. Eng Comput 27:225-233

4. Khandelwal M, Singh TN (2009) Prediction of blast-induced ground vibration using artificial neural network. Int J Rock Mech Min Sci 46:1214-1222

5. Hajihassani M, Jahed Armaghani D, Monjezi M et al (2015) Blastinduced air and ground vibration prediction: a particle swarm optimization-based artificial neural network approach. Environ Earth Sci. https://doi.org/10.1007/s12665-015-4274-1

6. Faradonbeh RS, Armaghani DJ, Amnieh HB, Mohamad ET (2016) Prediction and minimization of blast-induced flyrock using gene expression programming and firefly algorithm. Neural Comput Appl. https://doi.org/10.1007/s00521-016-2537-8

7. Ghoraba S, Monjezi M, Talebi N et al (2016) Estimation of ground vibration produced by blasting operations through intelligent and empirical models. Environ Earth Sci. https://doi.org/10.1007/ s12665-016-5961-2

8. Hajihassani M, Jahed Armaghani D, Marto A, Tonnizam Mohamad E (2015) Ground vibration prediction in quarry blasting through an artificial neural network optimized by imperialist competitive algorithm. Bull Eng Geol Environ. https://doi. org/10.1007/s10064-014-0657-x

9. Mohamad ET, Armaghani DJ, Hajihassani M et al (2013) A simulation approach to predict blasting-induced flyrock and size of thrown rocks. Electron J Geotech Eng 18 B:365-374
10. Jahed Armaghani D, Hajihassani M, Monjezi M et al (2015) Application of two intelligent systems in predicting environmental impacts of quarry blasting. Arab J Geosci. https://doi.org/10.1007/ s12517-015-1908-2

11. Armaghani DJ, Hajihassani M, Sohaei H et al (2015) Neurofuzzy technique to predict air-overpressure induced by blasting. Arab J Geosci 8:10937-10950. https://doi.org/10.1007/s1251 7-015-1984-3

12. Hasanipanah M, Jahed Armaghani D, Khamesi H et al (2016) Several non-linear models in estimating air-overpressure resulting from mine blasting. Eng Comput. https://doi.org/10.1007/s0036 6-015-0425-y

13. Bajpayee TS, Rehak TR, Mowrey GL, Ingram DK (2004) Blasting injuries in surface mining with emphasis on flyrock and blast area security. J Safety Res 35:47-57

14. Jahed Armaghani D, Tonnizam Mohamad E, Hajihassani M et al (2016) Evaluation and prediction of flyrock resulting from blasting operations using empirical and computational methods. Eng Comput. https://doi.org/10.1007/s00366-015-0402-5

15. Roy PP (2005) Rock blasting: effects and operations. CRC Press, Boca Raton

16. Ghasemi E, Sari M, Ataei M (2012) Development of an empirical model for predicting the effects of controllable blasting parameters on flyrock distance in surface mines. Int J Rock Mech Min Sci 52:163-170. https://doi.org/10.1016/j.ijrmms.2012.03.011

17. Rezaei M, Monjezi M, Yazdian Varjani A (2011) Development of a fuzzy model to predict flyrock in surface mining. Saf Sci 49(2):298-305

18. Roth JA (1979) A model for the determination of flyrock range as a function of shot condition. US Department of Commerce NTIS rep no PB81222358, p 61

19. Lundborg N, Persson A, Ladegaard-Pedersen A, Holmberg R (1975) Keeping the lid on flyrock in open-pit blasting. Eng Min J 176:95-100

20. Hasanipanah M, Jahed Armaghani D, Bakhshandeh Amnieh H et al (2016) Application of PSO to develop a powerful equation for prediction of flyrock due to blasting. Neural Comput Appl. https://doi.org/10.1007/s00521-016-2434-1

21. Faradonbeh RS, Jahed Armaghani D, Monjezi M (2016) Development of a new model for predicting flyrock distance in quarry blasting: a genetic programming technique. Bull Eng Geol Environ. https://doi.org/10.1007/s10064-016-0872-8

22. Amini H, Gholami R, Monjezi M, Torabi SR, Zadhesh J (2012) Evaluation of flyrock phenomenon due to blasting operation by support vector machine. Neural Comput Appl 21(8):2077-2085

23. Marto A, Hajihassani M, Jahed Armaghani D et al (2014) A novel approach for blast-induced flyrock prediction based on imperialist competitive algorithm and artificial neural network. Sci World J. https://doi.org/10.1155/2014/643715

24. Saghatforoush A, Monjezi M, Faradonbeh RS, Armaghani DJ (2016) Combination of neural network and ant colony optimization algorithms for prediction and optimization of flyrock and back-break induced by blasting. Eng Comput 32:255-266

25. Ahmad M, Ansari MK, Sharma LK et al (2017) Correlation between strength and durability indices of rocks-soft computing approach. Procedia Eng 191:458-466

26. Sirdesai NN, Singh A, Sharma LK et al Development of novel methods to predict the strength properties of thermally treated sandstone using statistical and soft-computing approach. Neural Comput Appl 1-27

27. Singh R, Umrao RK, Ahmad M et al (2017) Prediction of geomechanical parameters using soft computing and multiple regression approach. Measurement 99:108-119

28. Sharma LK, Vishal V, Singh TN (2017) Developing novel models using neural networks and fuzzy systems for the prediction of 
strength of rocks from key geomechanical properties. Measurement 102:158-169

29. Sharma LK, Vishal V, Singh TN (2017) Predicting $\mathrm{CO}_{2}$ permeability of bituminous coal using statistical and adaptive neurofuzzy analysis. J Nat Gas Sci Eng 42:216-225

30. Sharma LK, Singh R, Umrao RK et al (2017) Evaluating the modulus of elasticity of soil using soft computing system. Eng Comput 33:497-507

31. Sharma LK, Singh TN (2017) Regression-based models for the prediction of unconfined compressive strength of artificially structured soil. Eng Comput 1-12

32. Lee Y, Oh SH, Kim MW (1991) The effect of initial weights on premature saturation in back-propagation learning. In: IJCNN91-Seattle international joint conference on neural networks, vol 1. IEEE, pp 765-770

33. Jahed Armaghani D, Hajihassani M, Marto A et al (2015) Prediction of blast-induced air overpressure: a hybrid AI-based predictive model. Environ Monit Assess. https://doi.org/10.1007/s1066 1-015-4895-6

34. Tonnizam Mohamad E, Hajihassani M, Jahed Armaghani D, Marto A (2012) Simulation of blasting-induced air overpressure by means of Artificial Neural Networks. Int Rev Model Simul 5:2501-2506

35. Jahed Armaghani D, Shoib RSNSBR., Faizi K, Rashid ASA (2017) Developing a hybrid PSO-ANN model for estimating the ultimate bearing capacity of rock-socketed piles. Neural Comput Appl. https://doi.org/10.1007/s00521-015-2072-z

36. Mohamad ET, Armaghani DJ, Momeni E et al (2016) Rock strength estimation: a PSO-based BP approach. Neural Comput Appl 1-12. https://doi.org/10.1007/s00521-016-2728-3

37. Monjezi M, Khoshalan HA, Varjani AY (2012) Prediction of flyrock and backbreak in open pit blasting operation: a neuro-genetic approach. Arab J Geosci 5:441-448

38. Saemi M, Ahmadi M, Varjani A (2007) Design of neural networks using genetic algorithm for the permeability estimation of the reservoir. J Pet Sci Eng 59:97-105

39. Jahed Armaghani D, Mohd Amin MF, Yagiz S et al (2016) Prediction of the uniaxial compressive strength of sandstone using various modeling techniques. Int J Rock Mech Min Sci. https:// doi.org/10.1016/j.ijrmms.2016.03.018

40. Raina AK, Chakraborty AK, More R, Choudhury PB (2007) Design of factor of safety based criterion for control of flyrock/ throw and optimum fragmentation. J Inst Eng India 87:13-17

41. McKenzie CK (2009) Flyrock range and fragment size prediction. Proc. 35th Annu. Conf. Explos. Blasting Tech. 2

42. Trivedi R, Singh TN, Raina AK (2014) Prediction of blast-induced flyrock in Indian limestone mines using neural networks. J Rock Mech Geotech Eng 6:447-454

43. McCulloch WS, Pitts W (1943) A logical calculus of the ideas immanent in nervous activity. Bull Math Biophys 5:115-133

44. Yilmaz I, Yuksek A (2008) An example of artificial neural network (ANN) application for indirect estimation of rock parameters. Rock Mech Rock Eng 41:781-795

45. Mohamad ET, Jahed Armaghani D, Momeni E, Alavi Nezhad Khalil Abad SV (2014) Prediction of the unconfined compressive strength of soft rocks: a PSO-based ANN approach. Bull Eng Geol Environ. https://doi.org/10.1007/s10064-014-0638-0

46. Hasanipanah M, Noorian-Bidgoli M, Jahed Armaghani D, Khamesi H (2016) Feasibility of PSO-ANN model for predicting surface settlement caused by tunneling. Eng Comput. https://doi. org/10.1007/s00366-016-0447-0

47. Ahmadi MA, Ebadi M, Shokrollahi A, Majidi SMJ (2013) Evolving artificial neural network and imperialist competitive algorithm for prediction oil flow rate of the reservoir. Appl Soft Comput 13:1085-1098
48. Rukhaiyar S, Alam MN, Samadhiya NK (2017) A PSO-ANN hybrid model for predicting factor of safety of slope. Int J Geotech Eng 1-11

49. Holland JH (1975) Adaptation in natural and artificial systems: an introductory analysis with applications to biology, control, and artificial intelligence. MIT press, Cambridge

50. Goldberg DE (1989) Genetic algorithms in search, optimization, and machine learning. Read. Addison-Wesley, Boston

51. Momeni E, Nazir R, Armaghani DJ, Maizir H (2014) Prediction of pile bearing capacity using a hybrid genetic algorithm-based ANN. Measurement 57:122-131

52. Khandelwal M, Armaghani DJ (2016) Prediction of drillability of rocks with strength properties using a hybrid GA-ANN technique. Geotech Geol Eng 34:605-620. https://doi.org/10.1007/ s10706-015-9970-9

53. Beiki M, Majdi A, Givshad AD (2013) Application of genetic programming to predict the uniaxial compressive strength and elastic modulus of carbonate rocks. Int J Rock Mech Min Sci 63:159-169

54. Mohamad ET, Faradonbeh RS, Armaghani DJ et al (2016) An optimized ANN model based on genetic algorithm for predicting ripping production. Neural Comput Appl 1-14

55. Kennedy J, Eberhart RC (1997) A discrete binary version of the particle swarm algorithm. In: 1997 IEEE international conference on systems, man, and cybernetics, vol 5. IEEE, pp 4104-4108

56. Hasanipanah M, Shahnazar A, Bakhshandeh Amnieh H, Jahed Armaghani D (2017) Prediction of air-overpressure caused by mine blasting using a new hybrid PSO-SVR model. Eng Comput. https://doi.org/10.1007/s00366-016-0453-2

57. Atashpaz-Gargari E, Lucas C (2007) Imperialist competitive algorithm: an algorithm for optimization inspired by imperialistic competition. In: 2007 IEEE congress on evolutionary computation, CEC 2007. IEEE, pp 4661-4667

58. Hajihassani M, Jahed Armaghani D, Marto A, Tonnizam Mohamad E (2014) Ground vibration prediction in quarry blasting through an artificial neural network optimized by imperialist competitive algorithm. Bull Eng Geol Environ 74:873-886. https ://doi.org/10.1007/s10064-014-0657-x

59. Armaghani DJ, Hasanipanah M, Mohamad ET (2016) A combination of the ICA-ANN model to predict air-overpressure resulting from blasting. Eng Comput 32:155-171. https://doi.org/10.1007/ s00366-015-0408-z

60. Armaghani DJ, Mohamad ET, Narayanasamy MS et al (2017) Development of hybrid intelligent models for predicting TBM penetration rate in hard rock condition. Tunn Undergr Sp Technol 63:29-43. https://doi.org/10.1016/j.tust.2016.12.009

61. Bashir ZA, El-Hawary ME (2009) Applying wavelets to shortterm load forecasting using PSO-based neural networks. IEEE Trans Power Syst 24:20-27

62. Lin C-J, Hsieh M-H (2009) Classification of mental task from EEG data using neural networks based on particle swarm optimization. Neurocomputing 72:1121-1130

63. Taghavifar H, Mardani A, Taghavifar L (2013) A hybridized artificial neural network and imperialist competitive algorithm optimization approach for prediction of soil compaction in soil bin facility. Measurement 46:2288-2299

64. Yagiz S, Karahan H (2011) Prediction of hard rock TBM penetration rate using particle swarm optimization. Int J Rock Mech Min Sci 48:427-433

65. Jahed Armaghani D, Hasanipanah M, Mahdiyar A et al (2016) Airblast prediction through a hybrid genetic algorithm-ANN model. Neural Comput Appl. https://doi.org/10.1007/s0052 1-016-2598-8

66. Liou S-W, Wang C-M, Huang Y-F (2009) Integrative discovery of multifaceted sequence patterns by frame-relayed search and hybrid PSO-ANN. J UCS 15:742-764 
67. Faradonbeh RS, Armaghani DJ, Monjezi M (2016) Development of a new model for predicting flyrock distance in quarry blasting: a genetic programming technique. Bull Eng Geol Environ 75:993-1006

68. Zorlu K, Gokceoglu C, Ocakoglu F et al (2008) Prediction of uniaxial compressive strength of sandstones using petrography-based models. Eng Geol 96:141-158

69. Clerc M, Kennedy J (2002) The particle swarm-explosion, stability, and convergence in a multidimensional complex space. IEEE Trans Evol Comput 6:58-73
70. Shams S, Monjezi M, Majd VJ, Armaghani DJ (2015) Application of fuzzy inference system for prediction of rock fragmentation induced by blasting. Arab J Geosci 8:10819-10832

71. Armaghani DJ, Mahdiyar A, Hasanipanah M et al (2016) Risk assessment and prediction of flyrock distance by combined multiple regression analysis and monte carlo simulation of quarry blasting. Rock Mech Rock Eng 49:1-11. https://doi.org/10.1007/ s00603-016-1015-z

\section{Affiliations}

\section{Mohammadreza Koopialipoor $^{1} \cdot$ Ali Fallah ${ }^{2} \cdot$ Danial Jahed Armaghani $^{3} \cdot$ Aydin Azizi $^{4} \cdot$ Edy Tonnizam Mohamad $^{5}$}

Ali Fallah

ali.fallah@tabrizu.ac.ir

Danial Jahed Armaghani

danialarmaghani@aut.ac.ir

Edy Tonnizam Mohamad

edy@utm.my

1 Faculty of Mining and Metallurgy, Amirkabir University of Technology, 15914 Tehran, Iran

2 Faculty of Electrical and Computer Engineering, University of Tabriz, Tabriz, Iran
3 Faculty of Civil and Environmental Engineering, Amirkabir University of Technology, 15914 Tehran, Iran

4 Engineering Department, German University of Technology, Muscat, Oman

5 Faculty of Civil Engineering, Centre of Tropical Geoengineering (GEOTROPIK), Universiti Teknologi Malaysia, 81310 Johor Bahru, Malaysia 